\title{
Textualización de la verdad y crisis de la tradición en El castillo, de Franz Kafka
}

\section{Textualization of the truth and crisis of the tradition in The castle, of Franz Kafka}

\author{
Jefferson Eduardo da Paz Barbosa \\ Universidade Federal do Rio Grande do Norte, Brasil
}

Resumen: El objetivo de este artículo es identificar en la escritura/lectura de Franz Kafka, a partir de El Castillo, la intersección entre la problemática de la crisis de la tradición, planteada por Walter Benjamin y Gershom Scholem, y la textualización de la verdad que se desprende de las prácticas exegéticas en la tradición mística del judaísmo, sobre todo en la teoría cabalística del lenguaje. Siguiendo la discusión de las principales teorías presentes en el referencial bibliográfico, analizaremos cómo la escritura en Kafka utiliza el comentario como método, fundiendo exégesis y creación literaria. Podemos concluir que la verdad, en Kafka, se encuentra inseparable del texto y del comentario, lo que nos remite al Nombre de Dios infinitamente interpretable vislumbrado por la tradición mística de la Cábala. En la escritura de Kafka, la verdad inseparable del laberinto de interpretaciones apunta a la crisis de la tradición como característica esencial de su modernidad, expresando los límites entre religión y nihilismo.

Palabras clave: lenguaje, literatura, tradición, interpretación, Kafka. 
Abstract: The objective of this paper is to identify in the writing/reading of Franz Kafka, from The Castle, the intersection between the problem of the crisis of tradition, raised by Walter Benjamin and Gershom Scholem, and the textualization of the truth that emerges from exegetical practices in the mystical tradition of Judaism, especially in the kabbalistic theory of language. Following the discussion of the main theories present in the bibliographic reference, we will analyze how the writing in Kafka uses the commentary as method, merging exegesis and literary creation. We can conclude that the truth in Kafka is inseparable from the text and commentary, which brings us to the infinitely interpretable Name of God envisioned by the mystical tradition of Kabbalah. In Kafka's writing, the inseparable truth of the labyrinth of interpretations points to the crisis of tradition as an essential feature of its modernity, expressing the boundaries between religion and nihilism.

Keywords: Language, Literature, Tradition, Interpretation, Kafka.

Recibido: 4 de febrero de 2018

Aceptado: 25 de agosto de 2018

\section{Introducción: Franz Kafka, monstruo del laberinto hermenéutico}

Z n 1948, Jean-Paul Sartre afirmó: "De Kafka ya se ha dicho Ctodo: que quería describir la burocracia, la progresión de la enfermedad, la condición de los judíos en Europa oriental, la búsqueda de la inaccesible trascendencia, el mundo de la gracia cuando la gracia falta" (2004: 167). A pesar de eso, un levantamiento hecho en la década de los ochenta mostró que la fortuna crítica sobre la obra de Franz Kafka sobrepasaba la marca de los diez mil títulos. Sartre indica las principales líneas interpretativas de la obra de Kafka en la primera mitad del siglo xx, además de indicar que la interpretación es una de las cuestiones intrínsecas de esa obra. Kafka posee lo que Gershom Scholem llamó "luminosidad del ca- 
nónico" (1999: 229). Esto no sólo significa que es un clásico, incluso porque es uno de los autores menos imitables. Esta luminosidad es generalmente atribuida a los textos sagrados, cuyo mensaje es oscuro, o a los mitos, cuyo lenguaje es esencialmente ambiguo.

Pero este problema de la interpretación no se reduce al aspecto literario, al conflicto de las interpretaciones posibles del texto. Kafka se resiste a todo esto. En El castillo, por ejemplo, la práctica de extraer del texto su significado, o práctica exegética, es un procedimiento de escritura, es una máquina que hace que el texto crezca y se adentra como un bosque. En el mismo sentido, la exégesis $^{1}$ como obsesión y repetición es capaz de expresar algo mayor, tal vez lo que conocemos por visión kafkiana del mundo, el embate entre Ley y nihilismo ${ }^{2}$, Tradición y olvido.

Esta visión, que es dada a nosotros en su tesitura propia, es decir, en su lenguaje, presenta el problema básico de la experiencia hermenéutica: la interrogación implacable dirigida a lo que

${ }^{1}$ Observamos una obsesión por la exégesis en el texto de Kafka, pero se trata de una práctica muy común entre los estudiosos del Talmud. La exégesis es un modo de interpretación que no toma mucho en consideración el contexto inmediato o la literalidad del mensaje. A veces lo que decide un camino interpretativo es una homofonía, la raíz de una palabra, una letra. Por eso algunos autores, como Harold Bloom (Cabala e Crítica, Rio de Janeiro: Imago, 1991) y Susan Handelman (The slayers of Moses, Albany: New York Press, 1982), han identificado en algunas corrientes de la exégesis talmudica un posible origen de la crítica literaria contemporánea.

${ }^{2}$ Nihilismo no es únicamente el pensamiento obsesionado por la nada, sino una situación característica de la modernidad; de lo contrario, tanto Gorgias como Meister Eckhart serían pensadores nihilistas en la misma medida en que Nietzsche lo es. Nihilismo, propiamente como lo entendemos aquí y su efecto para una lectura de la obra de Kafka, se refiere a una situación de desorientación donde los referenciales tradicionales pierden su validez. Siguiendo el mayor teórico de la cuestión, Nietzsche, nihilismo es la desvalorización de todos los valores supremos (Volpi, 2005: 16). Veremos que la relación irónica de Kafka con los textos sagrados es genuinamente nihilista en el sentido moderno, haciéndolos insuficientes para legitimar el mundo ético. 
se plantea como verdad objetiva (trascendental y, no, histórica). De manera muy distinta, la obra de Kafka interroga el valor de la verdad, ora como un mensaje que nunca nos llega, ora como algo secreto que debe ser excavado indefinidamente, ora como el resultado improbable de una contestación infinita y absurda, ora como una fábula refutada. De todos modos, hay una distancia, sea la distancia infranqueable que el mensaje (el envío de una instancia objetiva) debe recorrer, sea la distancia del espacio laberíntico interpuesto por el texto que separa intérprete y revelación. La distancia y el espacio donde la verdad se extravía podrían representar una experiencia trágica, pero en ese espacio abierto se da el contentamiento de Kafka y los artificios de su escritura.

Durante seis meses del año 1922, Franz Kafka escribió los fragmentos que conocemos bajo el título de El Castillo, publicado póstumamente por Max Brod, en 1926. ${ }^{3}$ Básicamente, su trama trata de los diversos intentos de K. en su propósito de entrar en el Castillo. Lo que lleva a K. hasta la aldea es su nombramiento de topógrafo, pero su admisión no es clara, ya que parece haber sido un error cometido por algún funcionario o sector del Castillo. Los obstáculos que K. encuentra en su camino son incomprensibles, llenos de paradojas, como si no pudiera alcanzar la lógica que rige la administración de su universo. Kafka no tenía la intención de hacerse comprender literalmente y eso es unánime en su fortuna crítica.

En un punto de vista, la postura inicial de K. es motivo suficiente para alentar las lecturas de Brod, Hans Schoeps y muchos otros sobre el significado del Castillo, a saber, que representa la

\footnotetext{
${ }^{3}$ Cuando nos referimos a los capítulos del libro es importante tener en cuenta que se trata del trabajo editorial de Brod sobre los fragmentos escritos por Kafka, que, como se sabe, pidió a su amigo que los destruyera. El Castillo, antes de la forma tal como lo conocemos hoy, en diversas publicaciones en diversas lenguas, eran "capítulos” sueltos y muchos de ellos con más de una versión.
} 
sed de la Gracia que los esfuerzos de K. intentan lograr. Walter Benjamin rechaza esa interpretación teológica por ser cómoda e incompatible con el texto literal en muchas ocasiones (1987: 153). Benjamin no identifica en Kafka cualquier tendencia a la conclusión y lo que más caracteriza tanto El Proceso como El Castillo es el aplazamiento. El acusado se arrastra a lo largo de su proceso sin que nunca la sentencia sea anunciada del mismo modo que K. es impedido por innumerables contratiempos que no le dejan hablar con las instancias superiores. Es ese retardo del fin que pone todas las interpretaciones en negativo. El destino de K. se retrasa desde el principio hasta las páginas finales, en que es llevado una vez más al laberinto de contratiempos que se interrumpe bruscamente.

Otro punto de vista anuncia tal vez lo contrario. La postura de K. ante el Castillo es la fascinación ejercida por el sentido y la verdad que está allí, pero no está disponible o entonces su inteligibilidad degeneró en una transmisión burocratizada, encarnada en figuras autoritarias y depreciables, como Klamm, el alcalde, Bürgel, Erlanger, etc. Si K. se muestra tan insistente en comprender esa verdad, aunque su sustancia parezca diluirse en la total ausencia de significado último, es porque se mantiene como posibilidad de la redención una vez comprendida. Pero es porque el aplazamiento de esa comprensión es infinito que la redención nunca llega.

En Kafka, el acusado o el forastero siguen presionados por una autoridad inflexible sin saber hasta cuándo. Tal vez hasta el punto en que ellos, padeciendo el sufrimiento de la espera, realicen lo que caracterizaría una ruptura mesiánica y, por consiguiente, una ruptura con la Ley. ${ }^{4}$ La salvación a través del pecado, la idea de

${ }^{4}$ Es precisamente en este punto que los anónimos kafkianos pueden ser leídos como cabalistas heréticos. De acuerdo con Scholem, las rupturas en el interior del judaísmo más restringido, el judaísmo rabínico, fueron alcanzadas por el mesianismo místico de los estudiosos cabalistas bajo la figura de Sabbatai Tzvi. La importancia de este dato es que en el siglo xvIII, un hombre llamado Jacob 
que la ley sólo enseñará toda su esencia cuando es subvertida, fue alimentada por el mesianismo sabbataísta, donde la Cábala se encuentra con los movimientos antinomistas en el interior del judaísmo, abriendo espacio para los movimientos heréticos y anárquicos surgidos en el siglo XVIII. ${ }^{5}$

De principio a fin el objetivo de K. es esclarecer su función y el único medio para eso es entrando en contacto con el Castillo. Esta condición puede caracterizar, según la interpretación de Hannah Arendt, el exilio judío, o el judío como paria en busca de la asimilación, pudiendo finalmente convertirse en indistinguible (2005: 66). Convertirse en funcionario del Castillo no es redimirse espiritualmente, sino ser liberado de la vida incierta y sin sentido que se mantiene al margen de la Ley. K. no exige derechos especiales, sólo quiere integrarse de forma regular. De hecho, no pide menos que eso, pero es justamente lo que le es rechazado. La redención también puede ser obtenida junto a los aldeanos, pero

Frank se considerará reencarnación del mesías. Para Frank, este mundo no fue creado por el verdadero Dios, pues si lo fuera todos seríamos eternos. Este mundo es falso y regido por leyes indignas, por lo que no pueden ser respetadas. Todas las leyes de este mundo deben ser violadas. Frank es una expresión genuina del nihilismo religioso, herético y anárquico que resultó del mesianismo judío (Scholem, 1989: 105).

${ }^{5}$ Este aspecto es relevante en la medida en que la forma en que la Torá es vista por los sabbataístas propició el surgimiento de figuras revolucionarias que veían en la ruptura de la ley un modo de realizar en la historia el reino de los justos. Entre esas figuras, están Franz Kafka, Walter Benjamin, Gershom Scholem, entre otros (Forster, 2008: 9). Una lectura que destaca los aspectos anarquista u utópico libertario de la obra de Kafka se puede encontrar en Löwy, Redençâo e Utopia, 1989, p. 67-84. En La Cábala y su simbolismo Scholem (2001) discute la relación entre lo místico y la autoridad religiosa. Reservada la debida complejidad de la cuestión, el místico se presenta como figura revolucionaria ante la autoridad religiosa constituida históricamente a partir de sus prácticas en el seno de la comunidad. Las corrientes místicas judías, asociadas a la Cábala, representan esa ruptura de alguna forma, como sugiere Scholem en sus "Dez teses a-históricas sobre a Cábala” (1999). 
sólo en apariencia, lo que nos remite a la propuesta que Pepi hace a K. en el último capítulo, insistiendo para que él, sin abandonar la condición de forastero, fuera a vivir en las bodegas de alguna casa (Kafka, 2000: 447). La novela se interrumpe sin saber cuál es su decisión. K. no sería, según esa visión, un antinomista, alguien que niega las leyes impuestas, sino alguien que busca vivir bajo ellas de manera justa y humana.

Una parte de la crítica en torno a Kafka vincula la actitud de sus héroes a la visión gnóstica del mundo. ${ }^{6}$ También sería el caso de no encontrar respaldo textual, lo que no invalida una aproximación donde se considere su estructura. La relación con la visión gnóstica del mundo no es incoherente cuando observamos en el gnosticismo y en la gnosis herética de Jacob Frank, por ejemplo, la consideración del mundo como un lugar infernal administrado por leyes indignas (Scholem, 1999: 180). La relación con el gnosticismo puede ir desde una evocación de Brod en sus memorias ${ }^{7}$ hasta afirmaciones más puntuales en la interpretación de Günther Anders (2007). Cuando observamos el carácter plurívoco de la autoridad en Kafka y sus efectos en el mundo y en los personajes, somos conducidos a una teodicea, donde la existencia del mal es incompatible con la existencia de Dios. El origen del mal en el

\footnotetext{
${ }^{6}$ En adelante usamos como ejemplo de visión gnóstica del mundo la doctrina de Marción de Sinope.

${ }^{7}$ Walter Benjamin cita un fragmento donde Brod narra una conversación con Kafka: "Recuerdo una conversación con Kafka, cuyo punto de partida fue la Europa contemporánea y la decadencia de la humanidad. Somos, dijo, pensamientos nihilistas, pensamientos suicidas, que surgen en la cabeza de Dios. Esta frase evocó en mí en principio la visión gnóstica del mundo: Dios como un demiurgo perverso, y el mundo como su pecado original. Oh no, dijo, nuestro mundo es sólo un mal humor de Dios, uno de sus malos días. ¿Existiría entonces esperanza, fuera de ese mundo de apariencias que conocemos? Él se rió: hay esperanza suficiente, esperanza infinita, pero no para nosotros" (Benjamin, 1987: 141-142).
} 
mundo sólo podría derivarse de un "Dios malo", de un demiurgo, como lo llamaron algunos gnósticos. Por eso Anders afirma ser Kafka un marcionista, es decir, un adepto o simpatizante de las ideas de Marción de Sinope, el heresiarca del siglo II, d. C. para quien el Dios del Antiguo Testamento era radicalmente distinto del Dios anunciado por Jesucristo, siendo el primero el Dios de la Ley y de la Creación (por lo tanto, un Dios maligno) y el segundo, el Dios de la redención. ${ }^{8}$ En cuanto a la estructura del relato gnóstico, podemos sugerir que es un tema caro al imaginario kafkiano la necesidad de rebelarse o no contra la Ley, sobre todo cuando ésta parece emanar de una instancia ajena a la justicia, resultado del acto irracional de algún demiurgo.

Sea Kafka un gnóstico, un "ateo avergonzado" (Anders, 2007: 97) o un cabalista herético, la complejidad de sus relaciones con la religiosidad se levanta en torno al propio judaísmo bajo el cual creció. Los estudios de la lengua hebrea y sus abismos, sus "facetas impenetrables", como escribe en una carta a Felice Bauer (Alter, 2002: 67), sus incursiones en la dialéctica talmúdica, fueron maneras de tomar parte en algo auténtico, enteramente distinto del mundo burgués insípido. Sin embargo, según Robert Alter (2002: 80 ), sus novelas y cuentos no presentan, al menos en su superficie,

8 "En Kafka revive, de hecho, la idea, marcionista, según la cual el Dios-creador es 'demiúrgico', por lo tanto, 'malo', y la correspondencia es tanto más sorprendente que, en Marciáo, ese Dios-creador (de forma que el Dios del amor es al mismo tiempo el Dios de la 'Ley', del Antiguo Testamento: también en Kafka coinciden la instancia divina, la ley y la 'maldad'” (Anders, 2007: 118). La tesis de Claudio Willer, sobre poesía y gnosis, provee la información de cierto círculo marcionista frecuentado por Kafka y sus amigos (Willer, 2007: 8). Esta visión también es apuntada por Corngold; Breno, "Kafka (with Nietzsche) as neognostic thinkers", en Kafka: The ghost in the machine (2011). Para el caso de la gnosis marcionista y la Cábala revolucionaria de Kafka, ver Éric Lecler (2013: 235). Sobre la visión gnóstica del mundo, ver Hans Jonas, La religión gnóstica (2000). 
ningún indicio de que el escritor es judío, aunque detrás de toda su ambientación moderna salte a los ojos temas propiamente judíos, como el exilio, la asimilación, la revelación, el comentario, la ley y la tradición.

Así como los héroes de Kafka fracasan en el intento de interpretar lo insondable (el Tribunal, el Castillo, la Ley), el lector queda sin respuesta definitiva. El hilo de Ariadna suele perderse en medio del camino. En el mundo kafkiano, como en la experiencia de sus investigadores, los mensajes se resisten a la interpretación, tal como se comprende en el judaísmo; como destacó Benjamin, en Kafka las fábulas están destituidas de sus llaves (1987: 148). Tal vez sea un rasgo del judaísmo en Kafka el presentar un lenguaje que por ser humano ya no puede decir la verdad, forzando a la peregrinación a través del laberinto que resultó de la Caída. O tal vez esté más cerca de cierta visión de la Cábala luriana, donde cada palabra de la Torá posee seiscientos mil rostros, planos de sentido o entradas, de acuerdo con el número de hijos de Israel que se encontraban en el monte Sinaí. Así, de pronto, estamos frente al laberinto hermenéutico que Kafka, de manera ambigua -es decir, crítica-, absorbió de su tradición.

\section{Kafka, Benjamin y Scholem: la tradición como laberinto}

Nada es más evidente en El castillo que su mundo laberíntico. No son, sin embargo, laberintos como estructuras arquitectónicas, pues la aldea es un pequeño aglomerado en las proximidades del Castillo. Muchos podrían afirmar que ese mundo frío y gris es el infierno, el inframundo, con todos sus laberintos. En el laberinto de Kafka no existe ninguna posibilidad de salvación, pues no se trata de franquear muros, sino de encontrar una verdad que se perdió, tal vez para siempre, en el volumen de sus comentarios, o que permanece guardada por una administración oscura cerrada 
sobre sí misma, inaccesible, cuya autoridad fraccionada y jerarquizada está vacía de propósito real. El mensajero en el cuento "Un mensaje imperial” (Kafka, 2003: 202) es otro K., otro anónimo en los laberintos de la vida. El emperador, en el lecho de muerte, le envió un mensaje, pero nunca llegará a su destino (a propósito, es de un hombre muerto, posible metáfora de Dios, que se espera el mensaje), porque ni siquiera consigue atravesar todas las estancias del palacio, "nunca las dejará atrás; y aunque lo consiguiera, no se habría ganado nada; tendría que atravesar los patios, el segundo palacio circundante; y otra vez escaleras y patios; y otra vez un palacio; y así a lo largo de milenios" (2003: 202).

El laberinto de K. se compone de comentarios, de varias versiones sobre el Castillo contadas por los moradores de la aldea. Este laberinto exegético expresa de alguna manera la relación de Kafka con el judaísmo, que Benjamin vislumbró bajo el signo de una "enfermedad de la tradición" donde la verdad pierde toda su consistencia.

Por muchos años, Benjamin y Scholem mantuvieron una correspondencia cuyo centro fue la interpretación de la obra de Kafka. Entre las muchas ideas que los dos intelectuales levantaron, no podemos dejar de destacar la cuestión del distanciamiento de la tradición y la nada de la Revelación. La "enfermedad de la tradición”, apuntada por Benjamin, resulta de la secularización que aclimató (en su proceso de asimilación) a las familias judías a la ciudad burguesa moderna. Cuando Kafka se queja de su padre por el judaísmo mediocre que le fue transmitido (1997), queda bastante clara la crisis espiritual y política de su tiempo. Su mundo ficticio está despojado de todos los ornamentos de la tradición, aun manteniendo, de forma problemática, la tríada judía: la Ley, la Revelación y el comentario (Alter, 2002: 38). Podemos leer en una carta de Benjamin: 
Kafka escuchaba atentamente la tradición, y quien aguza el oído, no ve. [...] Esa escucha es intensa sobre todo porque al que escucha sólo le llega lo menos claro. Entonces no hay doctrina para aprender ni ciencia que se pueda conservar. Lo que debe ser capturado en el vuelo no son cosas que estén destinadas a un oído. Esto implica un estado de cosas que caracteriza rigurosamente la obra de Kafka en su parte negativa. (Su parte negativa será, desde ahora, mucho más rica en posibilidades que la positiva). La obra de Kafka representa una enfermedad de la tradición (Benjamin/ Scholem, 1987: 227).

Los dos críticos están en desacuerdo en muchos puntos. Benjamin rechaza la interpretación teológica practicada por Scholem, aunque despierte su interés en algún momento. Lo que en verdad repugnaba a Benjamin era la teología positiva que Brod formó alrededor de Kafka. En el caso de Scholem, el sentido positivo de la Revelación estaba perdido, lo que lo hacía más cercano a una especulación a los moldes de la teología negativa (Mòses, 1997: 182).

Scholem escribe: "El mundo de Kafka es el mundo de la Revelación, claro que en la perspectiva en la que se dirige de nuevo a su propia nada" (Benjamin/Scholem, 1987: 131). Es importante entender que esa nada no se refiere solamente a la ausencia de Dios, sino a lo que implica. Lo que es revelado en el judaísmo, lo que es emanado de la voz de Dios y es recibido por Moisés es la Torá, es decir, la Ley o Doctrina. Lo que Scholem está diciendo, por lo tanto, es que en el mundo de Kafka la Ley perdió la sustancia de su autoridad. En sus novelas la Ley existe y es válida, pero ya no tiene significado, está vacía. En respuesta a Benjamin, él escribe aún:

Preguntas lo que entiendo por "Nada de la revelación". Me refiero a un estado en que esta aparece vacía de significado, en lo que si bien se afirma y es válida, no obstante, no significa. Cuando falta la riqueza de la significación y lo que se manifiesta, reducido a un punto cero de contenido propio, sin embargo, no se desvanece (y 
la revelación es algo que se manifiesta), entonces surge su nada (Benjamin/Scholem, 1987: 145).

Benjamin entiende la secularización como índice de que la tradición ya no puede ofrecer una explicación de lo real. Por eso su gradual olvido e inevitable desaparición. Scholem, que vio en la constitución del Estado de Israel un movimiento secularizador que haría naufragar el hebreo como lengua sagrada, no deja de defender que el problema de la tradición es su transmisibilidad, no su muerte. La Revelación se ha vuelto incomprensible, pero no significa que nunca más hablará a los hombres. El gran trabajo de Scholem fue revolver el suelo de la tradición, recuperando una antitradición olvidada que pasa por la Cábala herética y el nihilismo mesiánico. La tradición sufre fluctuaciones, pasa por períodos de silencio, y en eso consiste su historicidad.

Benjamin destaca en Kafka la presencia de los estudiantes incansables, siempre sumergidos en los libros, pero que perdieron la Escritura (Benjamin, 1987: 164). En otra carta, Scholem se refiere a ese pasaje y no está de acuerdo que la Escritura haya sido perdida. En realidad, los estudiantes son discípulos que ya no pueden descifrar (Benjamin/Scholem, 1987: 131). Scholem descubre en la Cábala una tradición rebelde a toda escritura, donde el conocimiento a ser transmitido no es un cuerpo doctrinal o una verdad última, sino un horizonte de lectura o interpretación. La dirección de lectura, al fijarse en la forma escrita, necesita otra clave interpretativa. Se llega al punto en que no hay nada que transmitirse sino la posibilidad de la transmisión (Mòses, 1997: 199). Es como un "velo de niebla" que Scholem ve la tradición mística judía, una tradición donde lo que se transmite es la transmisión misma (1999: 224). Si para Benjamin la consistencia de la verdad fue perdida, para Scholem ella sigue oculta. Kafka sería un amplio relato de ese ocultamiento, lanzando permanentemente la pregunta acerca de la verdad. Sus personajes no poseen la llave que podría abrir la 
puerta correcta del gran edificio de la Revelación y se pierden en el laberinto textual de los comentarios.

La obsesión de estos estudiantes puede ser comparable a la actitud del modernista en el pensamiento de Benjamin, cuando interpreta el cuadro de Paul Klee, Angelus Novus: ellos tienen la mirada siempre hacia el pasado, hacia el montón de ruinas que crece hasta el cielo, mientras los vientos de la historia los empujan hacia adelante. El ángel y los estudiantes anhelan volver y recomponer los fragmentos, pero la tempestad los lanzan cada vez más lejos (Benjamin, 1987: 226). En Kafka, esa lejanía está en el límite de lo inaccesible.

\section{No hay nada fuera del texto: la dilución exegética del mundo}

En Calle de mano única, Benjamin nos recuerda, en el fragmento "Porcelanas de China", el valor del arte chino de copiar libros. A diferencia del copista, cuya alma es comandada por el texto que lo ocupa, abriendo en su interior perspectivas que se adentran como un bosque, el "mero lector" obedece sólo a su libre devaneo aéreo. Escribe: "La fuerza del camino del campo es una si alguien camina por ella, otra si la sobrevuela de aeroplano. Así es también la fuerza de un texto, una si alguien lee, otra se lo transcribe" (Benjamin, 1987b: 15-16). Para el judaísmo, como cultura del Libro, no hay nada fuera del texto. Kafka, a quien tanto fascinó la dialéctica laberíntica de los textos talmúdicos, está más cerca de un copista chino que de un lector aéreo, lo que es bastante claro en sus varias versiones de Abraham y de la Torre de Babel, donde lanza otras perspectivas (incluso cómicas) sobre el texto canónico (Alter, 2002: 103).

Esta fuerza del texto, que aparece como plástica del comentario, domina las grandes narrativas de Kafka, estructuradas como 
un interminable ejercicio exegético, pero unido a su imaginación literaria. Sobre este aspecto de la narrativa kafkiana, Alter escribe:

El brillo peculiar de las novelas de Kafka está en fundir la creación narrativa y la exégesis, transformando la ficción en un constante ejercicio de contemplación de sus propios significados desconcertantes, donde un protagonista perplejo es retratado en medio del absurdo de sus esfuerzos de contemplación. Kafka trata la exégesis como un método cognitivo universal y de características propias, al mismo tiempo que parodia, planteando dudas en cuanto a la posibilidad de que se base en una verdad revelada (2002: 105).

De todas sus narrativas, El castillo es el paroxismo de esa obsesión por el texto, su mundo es atravesado y diluido por la exégesis, como si ésta fuera la única manera posible de relacionarse con la realidad y es sobre ese método, completamente inseguro, que reposa el conocimiento. Esta inseguridad está manifiesta en la estructura del enunciado, que sufre bifurcaciones en la forma del "eso o aquello", del "si por un lado eso, por otro aquello", una modalidad analítica a partir de la cual el texto se expande orgánicamente, es decir, a partir de sí mismo. En el primer capítulo la máquina interpretativa comienza. $K$. llega exhausto en la aldea y consigue un lugar para dormir, hasta que es despertado por un joven. Una llamada confirma la identidad de K. como agrimensor. Podemos leer en el texto:

K. escucha atentamente. Entonces el castillo lo había designado agrimensor. Por un lado eso era desfavorable a él, pues indicaba que en el castillo se sabía todo lo que era necesario saber a su respecto, las relaciones de fuerza habían sido pesadas y aceptaban la lucha sonriendo. Pero por otro lado eso también era propicio, pues a su ver probaba que lo subestimaban y que él tendría más libertad de lo que de principio podía esperar. Y si creían con su reconocimiento como agrimensor-desde el punto de vista moral, sin duda superior - conservarlo en un estado de miedo continuo, 
entonces ellos se equivocaban: eso le daba un leve temblor, pero era todo (Kafka, 2000:14).

K. intenta interpretar todo en su entorno, nada le escapa, ni siquiera los susurros, todo vacila en sus conjeturas y se mantiene bajo el riesgo del engaño, de la ilusión, de la falsa interpretación, como en su intento de interpretar una fotografía, en la segunda conversación con la dueña del albergue, que dice: "Usted interpreta todo mal, hasta el silencio" (Kafka, 2000: 117). En la primera conversación con Frieda, K. queda encantado con su figura. El narrador dice: "Sus manos eran, en efecto, pequeñas y delicadas, pero podrían también ser descritas como frágiles e insignificantes" (2000: 66). Como se percibe, todo se dispone como un mensaje a ser descifrado o contestado. En el segundo capítulo, K. recibe una carta del mensajero Barnabás, remitida por el "Jefe del Departamento X”, dándole alguna información sobre su servicio. Esta carta, en realidad un pequeño billete, es sometida a un denso trabajo exegético. Esto sucede a lo largo de toda la novela.

Así comienza el pasaje: "No era una carta coherente" (Kafka, 2000: 39). K. ya plantea dudas sobre las intenciones del remitente, lee entre líneas la elección de los términos, el orden de las informaciones. Todo tiene un significado relevante, lo que hace del texto un bosque denso y lleno de trampas, con muchas entradas y salidas. Continúa:

En parte lo trataba como si fuera un hombre libre cuya independencia era reconocida: la manera de dirigirse a él, por ejemplo, y la referencia a sus deseos; pero había otras en que él era directa o indirectamente tratado como un empleado sin categoría, desconocido de los jefes de departamentos; el autor intentaría esforzarse para "no perderlo de vista" [...]. Eran incoherencias, no había dudas en cuanto a eso. Eran tan obvias que sólo podían ser intencionales. Ante tal administración, jamás se debían a una 
indecisión, y tal idea ni pasó por la cabeza de K. Este se inclinaba más a interpretar la carta como una opción que le ofrecían, dejando a su criterio hacer lo que quisiera de lo expuesto en la carta, es decir, convertirse en un empleado municipal, con una relación satisfactoria pero meramente aparente con el Castillo, o ser sólo en la apariencia un empleado municipal, cuya ocupación real sería determinada por los mensajes transmitidos por Barnabás (Kafka, 2000: 39).

La carta se interpreta en varios niveles, desde las intenciones del remitente, seleccionando partes del texto como citación directa, hasta la visión del empleador en ella expuesta. Además, el narrador no se priva de examinar las tendencias interpretativas de K., cuya visión está limitada por un aspecto u otro, así como es limitado todo punto de vista. A través de los elementos textuales, el narrador se adelanta y concluye el peligro que la carta anuncia: "Había, por supuesto, un peligro, y ese estaba suficientemente enfatizado en la carta, incluso elaborado con cierta satisfacción, como si fuera inevitable" (Kafka, 2000: 39). Era el peligro de hacer de K. un empleado, pues las expresiones usadas por el remitente, como "servicio", "superior", "trabajo", "términos de empleo", "responsabilidad”, sólo podían ser transmitidas desde el punto de vista de un empleador. Si hubiera un conflicto con las disposiciones del jefe, la carta deja muy claro, añade el exegeta, sólo K. lo habría iniciado. Esto está "sutilmente indicado" en la carta.

En una carta a su médico, Robert Klopstock, Kafka demuestra su habilidad para extraer del texto, en una lectura claramente subversiva, impresiones inusitadas. Crea una serie de anti-Abraham, mostrando un aspecto cómico del Génesis:

Pero imagine otro Abraham. Uno que quería realizar el sacrificio de la manera correcta, y tenía noción de la situación que era, en general, correcta, pero que, por otro lado, no podía creer que fuera él el escogido - él, un viejo feo, y el joven sucio que era su 
hijo. No le faltaba la verdadera fe, pues él tenía esa fe. Él haría el sacrificio de buen grado, si al menos pudiera creer que era él el elegido. Él tiene miedo de que, después de partir con su hijo como Abraham acabara transformándose en Don Quijote en el camino. El mundo habría tenido rabia de Abraham, si pudiera haberlo visto en la hora fatídica, pero éste aquí tenía miedo de que el mundo muriera de reír al verlo (Kafka apud. Alter, 2000: 110).

Sí, Kafka escribe a la luz de la revelación, pero de modo subversivo. Es uno de los procedimientos de Kafka revestir el mito de cotidianidad, o mejor, lanzar el mito en la historia. En su texto, el gran patriarca del monoteísmo occidental no puede cumplir su deber porque su casa nunca está ordenada, porque se pierde en los laberintos de la economía doméstica. El hombre que saldría de su casa y fundaría una religión bajo una ley suprema no conseguiría ni siquiera ser vendedor de ropas viejas.

La obsesión exegética de El castillo nos muestra que en el mundo kafkiano toda verdad está encubierta por muchas capas de significación, llegando al punto en que no hay conclusión o verdad definitiva, pues siempre una interpretación entra en conflicto con otra. ${ }^{9}$ No hay nada más que una infinita variación, una infinita plasticidad del comentario. En Kafka no hay un texto absoluto, un autor absoluto cuyo mensaje sea plenamente claro y fuera de duda. Esto no sólo revela su simpatía por el texto talmúdico, como comentario del comentario, con toda su complejidad retórica, como también lo coloca al lado de los cabalistas y los métodos interpretativos del Zohar. ${ }^{10}$

${ }^{9}$ Como escribe Stephane Mòses: “El castillo podría ser el ejemplo mismo de una obra que ya no trata de transmitir una forma determinada de la verdad, por el contrario, pone en escena, tanto a través del aspecto laberíntico de su fábula como por la fragmentación del discurso narrativo, la disolución de la idea misma de verdad" (Mòses, 1997: 197).

${ }^{10}$ La Cábala (término que significa "tradición") es un sistema de interpretación posterior al Midrash. Por siglos el pueblo judío sobrevivió sin patria, teniendo 
Por mantener en el límite entre religión y nihilismo, es poco clara la relación de Kafka con la verdad, aunque haya proyectado grandes ambiciones en su obra. La práctica del comentario es muy antigua entre los judíos y fue normalizada por los primeros rabinos, los doctores de la Ley. Y si ella fue consolidada junto al concepto fundamental de Tradición es porque mantiene el aspecto de la transmisibilidad. Scholem dice que "es el comentario, y no el sistema conceptual, es la forma legítima bajo la cual se puede llegar a la verdad" (2008: 84). La verdad está pre-contenida en el texto y de él debe ser arrancada. Esto sucede porque la Tradición, con el tiempo, deja de ser unitaria y pasa a admitir una infinidad de contradicciones. Continúa Scholem: "Lo que la Tradición abarca y con la máxima libertad afirma es precisamente esa riqueza en contradicciones, esa polifonía de opiniones que tienen que hacerse oír" (2008: 85).

\section{La verdad encarnada en el texto: conclusiones}

Maurice Blanchot, en un texto tardío sobre El Castillo, ya no considerando Kafka un escritor de la "soledad esencial", toca un punto que también observamos en Benjamin y Scholem. Reconoce que, a pesar de no tratar explícitamente de la Escritura como problema, ella forma parte de su estructura como ejercicio interminable del comentario. Lo impresionante en $\mathrm{K}$. no es que va inútilmente de un punto a otro de la aldea, sino que va de una exégesis a otra,

como única forma de cohesión el Libro. La práctica interpretativa de los judíos dio origen al Pentateuco, así como a los Midrashim, las interpretaciones de los rabinos antiguos sobre la Escritura, que posteriormente se incorporaron al Talmud. La Cábala es un sistema interpretativo destinado a extraer de la Torá un sentido místico, haciendo del libro un símbolo de la ley cósmica (Scholem, 2001: 9). Los estudios cabalísticos se consolidan con el surgimiento del Zohar, escrito por Moisés de León en el siglo XIII, una especie de revisionismo del mito de la creación judía. 
escuchando cada una de ellas atentamente. Todas las interpretaciones se someten a su examen, luego interviniendo y discutiendo interpretaciones alternativas. El capítulo "En la catedral", en $E l$ proceso, donde Joseph K. y el padre discuten la interpretación de la parábola "Ante la Ley", es similar al último capítulo de El castillo, donde Pepi teje un largo comentario sobre la relación entre K. y Frieda. En los dos casos, los héroes kafkianos cuestionan la interpretación presentada y ofrecen sus puntos de vista, haciendo del texto una superficie continuamente fracturada. De acuerdo con Blanchot, sería fácil comparar ese movimiento con la dialéctica talmúdica (2002: 164). La sucesión interminable de versiones exegéticas trata, al final de cuentas, de la posibilidad de interpretar $E l$ castillo - o, en último caso, de escribirlo. Blanchot escribe:

[...] El castillo no es sino eso, y la fuerza de las imágenes, la fascinación de las figuras, la atracción decisiva del relato constituyen su única verdad, verdad tal que siempre parece decir más acerca de todo lo que se pueda decir, con lo que introduce el lector, pero antes que nada el narrador, a través de un tormento de un comentario sin fin (2002: 166).

El vacío que el Castillo representa parece decir más que todo lo que se pueda decir sobre él, pero también es verdad la afirmación inversa, de que él dice infinitamente menos. La precariedad que ronda la peregrinación de K. no se limita al interior de las casas de la aldea y a la condición miserable de los aldeanos. A pesar del exhaustivo comentario sobre el Castillo, todas las respuestas que se pueden obtener son insuficientes. El Castillo parece no existir sino en sus comentarios, pero éstos son siempre insuficientes. Para Blanchot es una instancia indiferente a toda evaluación, una instancia neutra. Colocar el neutro en lugar de la Ley, es tal vez una forma de abolir su misterio. Sin embargo, si sólo se mira el con- 
cepto, todavía se encuadra en una teología negativa del mysterium tremendum.

Si lo neutro es lo que no puede ser evaluado, no es finito ni infinito. Por otro lado, lo que el Castillo suscita es un comentario infinito, precario y fragmentado, de modo que sólo lo comprendemos a través de él, pues no tenemos acceso a la unidad pura, sino a la multiplicidad. El puesto de Absoluto ocupado por el Castillo también está ocupado por el Uno más allá de toda inteligibilidad. Sin duda, a primera vista, no habría nada más extraño al judaísmo ortodoxo que un Dios oculto, sin rostro e impersonal. No obstante, en la tradición mística de la Cábala, que según Scholem se desarrolla en los siglos XII y XIII, es posible encontrar las primeras alusiones a un Dios oculto dentro del judaísmo. ${ }^{11}$

Las religiones monoteístas se desarrollaron en el período medieval rodeadas por dos herencias en tensión: fuentes provenientes del mundo religioso canónico, cuyas escrituras fueron recibidas por revelación, y el mundo del pensamiento especulativo de la filosofía griega. En otras palabras, la tensión se arma entre el Dios de la Biblia (para el judío-cristianismo) y el Uno de Plotino. El Dios de la Biblia no es generado al cabo de un recorrido racional. Se da en la experiencia de la comunidad y en la revelación individual, o es dado como incontestable en la manifestación de la Creación. ${ }^{12}$ Es

${ }^{11}$ En realidad, un dualismo de Dios puede ser constatado en la antigüedad tardía. Scholem observa en varios momentos que el gnosticismo del siglo II d. C. también formó el pensamiento de algunos judíos helenizados. El teólogo judío alejandrino más cercano al gnosticismo fue Cerinto. Según Epifanio de Salamis, Cerinto fue el primer teólogo judío en enseñar la diferencia entre el Dios Supremo y el Dios Creador (Torrents, 2000: 24).

12 "Sus manifestaciones son tan tangibles que no necesitan ninguna prueba ulterior; los efectos de su poder son legibles en la naturaleza y en la historia, sobre todo en esta última, y cuando se oculta no es que por naturaleza sea oculto, sí porque nosotros no somos dignos de su revelación, porque extendemos a su alrededor un velo fabricado por nosotros mismos" (Scholem, 2008: 12). 
un Dios que tiene voluntad y conciencia incomprensibles, pero aprehensibles como Sabiduría. La revelación de Dios implica, por lo tanto, la revelación de su personalidad una. Precisamente contrario al Dios bíblico, el Uno de Plotino es ajeno a toda determinación y se alcanza al término de un camino filosófico.

Podemos concordar con Scholem y considerar Kafka un adepto de la Cábala, en el sentido de que no sostiene una visión mística del universo positivamente orientada en una doctrina. Una aproximación sólo es posible si consideramos la Cábala una corriente herética en el interior del judaísmo que mantuvo la Torá bajo constante indagación. Por ejemplo, el encuentro entre neoplatónicos y cabalistas resultó en una noción polémica de Dios: la unidad indiferenciada de lo que no tiene fin, o Ein-sof, ${ }^{13}$ que se manifiesta y revela en sus nombres, en su lenguaje, siendo una visión que contradice algunas corrientes de la interpretación rabínica sobre la naturaleza de Dios. Para los cabalistas, Dios es incompatible con cualquier atributo. Podemos leer en Scholem que, al hablar de la ausencia de significado del Nombre de Dios, apunta al problema de la tradición comentado hasta aquí:

El hecho de que el Nombre de Dios esté desprovisto de significación es un indicativo de su posición en el centro de la revelación, sirviéndole de base. Por detrás de toda revelación de un sentido en el lenguaje y, como los cabalistas dicen, a través de la Torá, se sitúa ese elemento más allá del sentido y que, al mismo tiempo,

${ }^{13}$ Ein-sof o Ain-sof, denota a Dios antes de su automanifestación, anterior a sus emanaciones (Sefirót). Es el absoluto impersonal cuya "existencia" no puede ser descrita por ningún atributo. Podemos leer en el Zohar: "Antes que Él diera cualquier forma al mundo, antes de que él produjera cualquier forma, Él estaba solo, sin forma y sin semejanza con cualquier otra cosa. ¿Quién entonces podrá comprender cómo Él era antes de la Creación? Así pues, está prohibido proporcionarle cualquier forma o semejanza, o incluso llamarlo por su nombre secreto, o indicarlo por una sola letra o un único punto" (Campani, 2011: 290). 
lo posibilita. Sin tener un sentido, él mismo confiere un sentido a todo. Lo que para nosotros es reconocible en la Creación, el Nombre de Dios, es infinitamente interpretable y se refleja en nuestro lenguaje. [...] Lo que tiene significado, sentido y forma, no es esa palabra propiamente, sino la tradición de esa palabra, su intermediación y reflexión en el tiempo. Esta tradición, que posee su propia dialéctica, se transforma y se convierte eventualmente en un susurro silencioso y bañador, pudiendo haber épocas, como la nuestra, donde cuando ya no puede ser más transmitida y cuando esa tradición enmudece (Scholem, 1999: 61).

Entre otros aspectos, lo que se dice en el pasaje es que no hay nada fuera de la tradición, el significado del Nombre de Dios, de la Torá, es su propia transmisión. Si Dios no está fuera de la Torá y la Torá no está fuera de Dios, se puede concluir que en la concepción cabalista del Nombre de Dios, que lo funde a su Revelación, no está fuera del texto (Idel, 2007: 114). Por eso Scholem encara la tradición como algo plástico de donde se puede extraer aún su fuerza viva en la medida en que en él se profundice. Las significaciones de Dios son posibles porque su unidad es inseparable de su textualidad; su unidad es inseparable de su encarnación en el múltiplo revelado. La infinidad de Dios en la tradición cabalística y el debilitamiento de la distinción de su persona aumentan la oscuridad de su mensaje, lo que proporciona, en consecuencia, la posición activa del exegeta.

El filósofo y místico cabalista judío más importante en esa concepción "textual” de Dios, concepción "textocéntrica”, diría Moshe Idel, ${ }^{14}$ fue Abraham Abuláfia, nacido en Zaragoza, en el siglo

${ }^{14}$ Moshe Idel compara la hermenéutica cabalística con algunas visiones contemporáneas del texto y de la lectura. Si para Roland Barthes la soberanía del lector implicaba la muerte del autor, que fue un movimiento similar al realizado por Jacques Derrida, al proponer la elipse de la autoría (de la presencia logocéntrica), para Moshe Idel lo que atribuye a la Cábala creativa la infinidad de 
XIII. La Cábala de Abuláfia tiene un doble aspecto que involucra prácticas meditativas: la Cábala extática y la Cábala de los Nombres de Dios. La contemplación de las letras del alfabeto hebreo y la recitación de los nombres de Dios es un método para alcanzar una experiencia mística fundamental, pero también un método exegético avanzado. La técnica de la combinación de las letras del alfabeto permite al místico acceder a los estratos más profundos de la Escritura (Idel, 1989: IX). La actitud de Abuláfia hacia Dios y la Torá atrajo la fama negativa que soportó en su siglo. La idea de que el secreto de la Escritura será alcanzado a partir de la permutación de sus frases y de sus letras, a fin de que nuevos significados surjan de su abismo, desenterrando todos los Nombres de Dios, puede ser vista como una forma de subversión y fue reconocida como práctica herética.

Si volvemos al texto de Kafka, observamos que la presencia del Castillo, como origen metafísico, nos permite concebir el lenguaje como exposición y desdoblamiento de su Nombre en la infinita plasticidad de sus comentarios. Por eso podemos entender la postura de K. como subversiva, en confrontación con todas las interpretaciones que le son presentadas, haciendo del diálogo no un recurso dramático, sino un medio agonista de poner en escena diferentes puntos de vista. Es por esa vía que una relación con la Cábala herética es posible.

Se nos lleva a concluir que el lenguaje tiende a ser cada vez más inepta para comunicar, usando palabras de Benjamin, el "contenido espiritual” (2007: 144) del mundo. Es en ese sentido que el

significados es la identificación entre el autor y el texto. Según él "es la presencia del autor infinito en el seno del texto canónico que garantiza la posibilidad de extraer una infinidad de significados. La idea de un Dios infinito atenúa el carácter distintivo de Su persona y la claridad de sus mensajes. Esto deja al lector la tarea de redefinir el tiempo así como el contenido del libro que está leyendo" (Idel, 2007: 116). 
lenguaje en la modernidad llega al extremo de su crisis, sea para el judaísmo, sea para la poesía europea. Este no es sólo un problema reflejado, por ejemplo, en el interés de Scholem por la lengua hebrea desde los quince años, bajo la alegación de que el alemán no podría jamás expresar el contenido de una lengua abisal; o en el interés de Kafka por las facetas impenetrables de la lengua sagrada. La crisis está reflejada en el escepticismo o la esperanza de que el lenguaje sea eficaz en lo que intenta expresar, sea el reflejo emitido en la obra de Samuel Beckett, sea en la obra de James Joyce. Este último, a propósito, es un caso impar, pues si la lengua en sus formas convencionales ya no puede transmitir lo esencial, debe ser arrancado mediante torsiones mórficas, sintácticas y semánticas (Alter, 2002: 90).

La concepción de una divinidad cuya palabra se oculta bajo seiscientos mil rostros, concepción que afirma al mismo tiempo su presencia y su ausencia, presencia que se da mediada por una distancia infinita, como la que separa el mensaje del emperador de su destinatario, es la que más conviene al nihilismo de Kafka y su cuestionamiento sin fin. Como pocos, Kafka "expresó los límites entre religión y nihilismo" (Scholem, 1999: 229). En nuestra época, él puede inspirarnos a profanar los textos sagrados, a torcerlos, no para que sean anulados, sino para que puedan, por la fuerza de la plasticidad que su fábula contiene, revelar sus sentidos.

Kafka reconocía que su búsqueda podría llevarlo a la locura. Su literatura era un "asalto a las fronteras" (Kafka, 1953: 385-386) y podría, como él dice, haberse desarrollado en una nueva doctrina secreta, en una nueva Cábala, si no fuera el movimiento sionista y el alejamiento de la Cábala mesiánica. Si su literatura fuera una nueva Cábala, que echaba raíces en los viejos siglos, asaltando las fronteras, comprendía su papel antinómico ante las doctrinas positivas, lo que lo haría, según Scholem, un cabalista herético. Escribir, lo sabía, es una práctica demoníaca. Pero no sabemos hasta qué 
punto Kafka comprendió su herejía. Ciertamente entendió que en el nihilismo mesiánico la salvación se da a través del pecado. Lo que sabemos es que él escribió para morir contento.

\section{Bibliografía}

Alter, Robert, 2002, Anjos necessários: tradição e modernidade em Kafka, Benjamin e Scholem, Andre Cardoso (trad.), Imago, Rio de Janeiro.

Anders, Günther, 2007, Kafka: Pró e contra, Modesto Carone (trad.), CosacNayf, São Paulo.

Arendt, Hannah, 2005, La tradición oculta, R. S. Carbô y Vicente G. Ibáńez (trad.), Paidós, Buenos Aires.

Benjamin, Walter, 1987, Magia e técnica, arte e política, Sergio Paulo Rouanet (trad.), Brasiliense, São Paulo.

, 1987b, Rua de mão única, Sergio Paulo Rouanet (trad.), Brasiliense, São Paulo.

, 2007, "Sobre el lenguaje en cuanto tal y sobre el lenguaje del hombre", en Obras, libro II, vol. I, Jorge Navarro Pérez (trad.), Abada Editores, Madrid.

Benjamin, Walter y Gershom Scholem, 1987, Correspondência 1933-1940, Francisco Rafael L. González (trad.), Trotta, Madrid.

Blanchot. Maurice, 2002, De Kafka a Kafka, Jorge Ferreiro (trad.), Editora Nacional, Madrid.

Campani, Carlos, 2011, Fundamentos da Cabala: Sêfer Yetsirá, Editora UfPel, Pelotas.

Forster, Ricardo, 2008, "La cabála y la travesía del mal", Revista Digital de Estudios Judaicos, Belo Horizonte, vol. 2, núm. 3, octubre, pp. 55-66. 
Idel, Moshe, 2007, "Jacques Derrida and kabbalistic sources", en Judeities: Questions for Jacques Derrida, Fordhan University Press, Estados Unidos, pp. 111-138.

, 1989, Language, Torah, and Hermeneutics in Abraham Abulafia, State University of New York Press, Nueva York.

Jonas, Hans, La religión gnóstica, Menchu Gutierrez (trad.), Siruela, Madrid.

Kafka, Franz, 1953, Diarios, J. R. Wilcock, Emecé (trad.), Buenos Aires.

, 1990, Cartas aos meus amigos, Patricia Fonseca (trad.), Nova Época, São Paulo.

, 1997, O Processo, Modesto Carone (trad.), Companhia das Letras, São Paulo.

, 1997, Carta ao pai, Modesto Carone (trad.), Companhia das Letras, São Paulo.

,2000, O Castelo, Modesto Carone (trad.), Companhia das Letras, São Paulo.

,2003, Obras Completas III: Narraciones y otros escritos, Jordi Llovet (trad.), Galaxia de Gutenberg, España.

Lecler, Éric, 2013, L'Absolu et la littérature: du romantisme allemand à Kafka, Classiques Garnier, París.

Löwy, Michael, Utopia e Redenção, Paulo Neves (trad.), Companhia das Letras, São Paulo.

Milmaniene, Magalí, 2007, La tradición mesiánica judia ya la influencia de Gershom Scholem en la obra de Walter Benjamin, Tese, Universidad de Buenos Aires, Buenos Aires.

Mòses, Stéphane, 1997, El ángel de la historia: Rosenzweig, Benjamin, Scholem, Alicia Martorell (trad.), Cátedra, Madrid.

Sartre, Jean-Paul, 2004, Que é a literatura?, Carlos Felipe Moisés (trad.), Editora Ática, São Paulo. 
Scholem, Gershom, 1989, "Do messianismo ao niilismo religioso”, Jacó Guinsburg (trad.), Revista USP, núm. 2, junio-julio. , 1999, Judaica III, Ruth Joana Solon y Jacob Guinsburg (trad.), Perspectiva, São Paulo. , 2001, La Cábala y su simbolismo, Carlos Peleiro (trad.), Siglo xxi, México.

,2001, Los orígenes de la cábala, Radamés Molina y Cesar Mora (trad.), Paidós, Barcelona. , 2008, Conceptos básicos del judaísmo, José Luis Barbero (trad.), Trotta, Madrid.

Torrents, José, 2000, Los gnósticos, Gredos, Madrid.

Willer, Claudio, 2010, Um obscuro encanto: gnose, gnósticos e poesia moderna, Civilização Brasileira, Rio de Janeiro. 